of texts in the study of this field and, more parochially, the gradual dissolution of that remarkably close linkage to the Roman Society to which the pages of its Jubilee Volume had borne witness; an increasing divergence from the practice of Roman archaeology in most other provinces of the Empire (with a few notable exceptions, such as that in the partially occupied Netherlands); a widening alienation from other branches of Classical archaeology.

Yet, to return for a moment to the first example of the Parthenon and its sculptures, these other branches of Classical archaeology have

\section{References}

ASHMOLE, B. 1962. Some nameless sculptors of the fifth century $\mathrm{BC}$, Proceedings of the British Academy 48: 213-33.

Fox, A., J.M.C. TOYNBEE, S.S. Frere \& J.K.S. ST JOSEPH; G.C BOON; R.E.M.WHEELER. 1968. Richmond, Wheeler and Hod Hill, Antiquity 42: 292-6.

Popham, M.R., E. Touloupa \& L.H. SAcKeTt. 1982. The hero of Lefkandi, Antiquity 56: 169-74. meanwhile begun to make their own changes, in roughly parallel directions, in Greece, Italy and the other Mediterranean lands. Few if any would propose abandoning such studies as the art of the Parthenon, but there is a detectable move to divert more of the collective effort to very different pursuits. Again, this has implied a degree of assimilation to the practices of prehistory. As someone who has devoted his later career to promoting such changes, I cannot forbear to salute the lead which Wheeler gave, all those years ago, and to the vital rôle which ANTIQUITY played in enabling him to do so.

SNODGRASS, A. \& C. ChIPPINDALE (ed.). 1988. Classical matters, Antiquity 62: 724-97.

WHEELER, R.E.M. 1961. Review of Journal of Roman Studies, vol. 50, Antiquity 35: 157-9.

1962. Size and Baalbek, Antiquity 36: 6-9.

1968. Review of I.A.Richmond, Hod Hill, vol.2, Antiquity 42: $149-50$.

\title{
The innocents and the sceptics: ANTIQUITY and Classical archaeology
}

\author{
Nicola Terrenato*
}

When I was invited to discuss ANTIQUITY and Classical archaeology, I felt I only had some general impressions to contribute, and they were also largely limited to the last 15 years of the journal, which I had encountered as an undergraduate on the shelves of the British School at Rome. Upon closer examination, these impressions turned out to consist mainly of the disturbing feeling that ANTIQUITY was an archaeological Parnassus that only a handful of us Greek and Roman archaeologists had been able to ascend. Senior Classicists may have thought more highly of other journals specializing in the sub-discipline, but for a lot of young Turks like myself ANTIQUITY had always been for archaeology what Nature was for the hard sciences. We thus concluded that if papers dealing with the Greek and Roman world were rather infrequent in the journal, this was simply another reflection of the systemic shortcomings of our sub-discipline. It seemed Classical archaeologists simply did not make the cut very often, and rightly so, since they seldom had anything to say that might interest the wider field of practitioners. We polemically maintained that this was due to the narrow-focused, idiosyncratic and uninspired research agendas that prevailed in the Classics. We had the painful feeling of being theoretically and methodologically impaired, compared to the stuff we were reading in the journal.

As I started gathering my thoughts to put them on paper, I realized that I had not changed my mind much, even after having had a peek at the editorial process behind the journal. Allowing for the wisdom and mellowing that age brings, I still seldom came across papers that I thought suitable for the journal. But in addition to that, having become infected with deconstructionism, I now wondered why things were the way they were and decided for a fresh data collection. While dutifully browsing

* Department of Classics, CB\# 3145, 101 Howell Hall, University of North Carolina, Chapel Hill NC 27599-3145, USA. 
through the bound volumes of ANTIQUITY, I realized that some key issues in our intellectual history were involved in the matter. Now there is no question that, generally speaking, the history of Antiquity is the history of 20thcentury archaeology. Leafing through the issues, you can still hear the hopes and the concerns, the clashes and the put-downs, the boos and the cheers, as in a congressional record. And really, the mark of a good journal is precisely the ability to move with the evolution of the discourse, wherever it may happen to go or drift. ANTIQUITY had been the preferred medium for many really significant exchanges of ideas.

On the specific matter of Classical archaeology, ANTIQUTTY's witness is of particular value. Not only is the peculiar parable of this subdiscipline all there, but nowhere are the complex interrelations and paradigm shifts illustrated as clearly. One can clearly see how the relationship between archaeologists and Classicists deteriorated over time, with the result that those who were once at the core of the discipline became a self-exiled and eventually dramatically down-sized minority. Although not frequently emphasized, this is one of the major phenomena of 20th-century archaeology (cf. Trigger 1989). A discipline that had been spawned, at least in part, by a collector's interest in Greek and Roman artefacts (Schnapp 1993), in time developed (or perhaps revealed) a deep rift separating precisely those cultural contexts from all the rest of the human past. Of course Classical studies had always had a peculiar position in the broader field of the 'sciences of the past', but as long as this was a clearly defined and somewhat dominant one, a measure of dialogue was kept alive. When, on the other hand, Classical archaeology entirely lost its preeminence, and became regarded as just another area of specialization, its practitioners went into an intellectual purdah from which most of them have not yet returned.

There is now a tendency to consider this a natural, or at least unavoidable, turn of events on both sides of the split. But it can be argued that there is still a lot of thinking to be done on this issue and in particular that deep-running and not particularly palatable ideological biases are still at work here. The ultimate goal of this paper, however, is absolutely not to call for the return of the good old days, within the journal or anywhere else. It is instead an at- tempt at reconsidering the recent evolution of Classical archaeology and the perspectives for its future, using ANTIQUITY as a starting-point or, rather, as a privileged peephole into the workings of a complex intellectual process.

But let us begin at the beginning. When ANTIQUITY first came into being, Classical archaeology figured among its core themes. Founding father Crawford had had some exposure to the Classics at Keble College and indeed many of his contributions, just as those by Mortimer Wheeler, adopted a long-term perspective that seamlessly included the Roman period and would influence a whole genre of local British archaeology. An excellent example of this is a paper discussing rural Britain's 'debt to Rome' (Crawford 1928), which also had important intellectual ramifications, discussed later. The contributors to the journal in its first decades, up to the war, included some of the most prominent names in British Classical studies: R.G. Collingwood (1927; 1930; 1932), of course, topographer Thomas Ashby (1928), numismatist Harold Mattingley (1934), pioneer Aegeanist A.J.B. Wace $(1936 ; 1940)$, etruscologist Randall McIver (1927; 1928a; 1928b), as well as a young John Ward-Perkins reporting on prehistoric Malta (1942). A wide range of foreign Classicists also regularly chipped in: Agora director Leslie Shear (1933), Thera discoverer Sp. Marinatos (1939), early Rome giant Einar Gjerstad (1928, but working in Cyprus at the time), Ostia excavator Guido Calza (1933). Thus, right from the start, the focus is upon field archaeology, but forays in ancient history, epigraphy, art and even philology are not excluded at all. Crawford himself, proving once more his amazing scholarly breadth, authors a review article on Sidonius Apollinaris in 1934. A significant predominance of Roman studies (with Italy and Britain receiving the lion's share) is confirmed by a rough tabulation of the paper topics (FIGURE 1; for the sake of comparison between different periods of the journal, only papers are counted throughout this contribution, excluding notes and news, reviews etc.; remarkably, a comparable number of papers (about 600) has been published in each of the three 25-years periods defined here: 1927-50, 1951-75, 1976-2000). The first quarter-century of the journal thus reflects in full the role that the Classics were perceived to have at the time, i.e. a constituent part of the discipline, which 

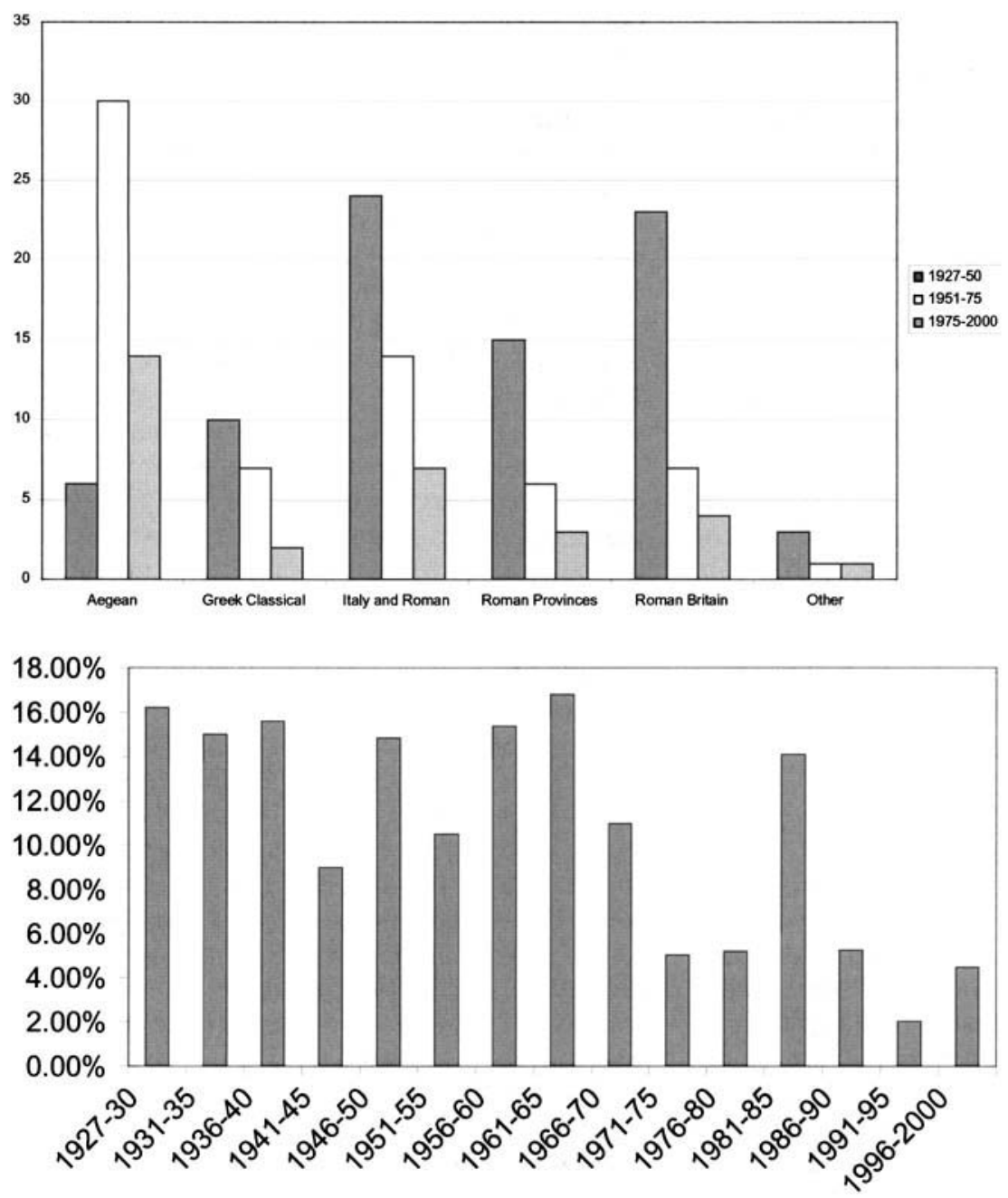

FIGURE 1. Breakdown of articles dealing with Classical archaeology by topic.
FIGURE 2. Percentages of Classical archaeology papers published per 5-year period. nobody could afford to ignore altogether. After all, in those days they still represented the first formative experience for many scholars in college, just as did Latin and Greek at the public schools nearly all of them had attended anyway.

The earliest signs of impending change are discernible immediately after the Second World War. While Classical archaeology still enjoyed its eminent position within the scholarship, there was a perceptible shift in the journal. The scene was stolen by the exciting epic of the decipherment of Linear B, in which the journal played an important role. Michael Ventris' and John Chadwick's revolutionary discovery is announced there in 1953 (Ventris 1953; Chadwick 1953), to be followed by a flurry of other contributions, that ranged from detailed textual analyses to historical and archaeological syntheses (Webster 1957; Chadwick 1959; Hood 1962). The journal at this stage was not only the premier venue for the booming field of Aegean archaeology, but it even registered on the radars of hardcore Classical philologists around the world. It was the perfect meetingplace for the diverse specialists that were engaged in the interdisciplinary effort to rediscover the Aegean Bronze Age. Because of its novelty and interest, it forced specialists to venture across the unbridgeable divide outside the enchanted kingdom of the Classics. In a similar way, elsewhere in the Mediterranean, new discoveries promoted a tighter relationship between Classical archaeology and its prehistory (e.g. Kathleen Kenyon's reports from Jericho (1952 and Carl Nylander's from Troy (1963)). 
In addition to the new Aegean adventure, the journal went on publishing high-profile contributions dealing with the Greek and Roman world. Gjerstad (1952) announced his big discoveries in the Roman Forum, Bradford's (1947; 1949) landmark contributions on airphoto interpretation were literally rewriting the landscape history of ancient Italy, Kevin White (1963; 1965) was breaking new ground on Roman agriculture. The list of contributors also includes a variety of remarkable people, from crossover geoarchaeologist Claudio Vita-Finzi (1961) to mainstream art historian John Boardman (1960), from Medievalist Richard Krautheimer (Krautheimer \& Corbett 1960) to Etruscologist Massimo Pallottino (1962), from Roman Britain big cheese Sheppard Frere (1964) to a young and promising Barry Cunliffe (1965; 1966) working at Bath and Fishbourne. In general, the quality of the papers and the renown of their authors was, if anything, higher than ever before. There is hardly a name that does not ring a bell today, and usually a pretty big one.

These appearances notwithstanding, there were deep-reaching transformations afoot, and their radical effects became manifest from the 1970 s onward. Things came to a head when the journal daringly embraced processualism, and entirely lost its innocence in the process. Other contributions in this special section discuss the key role that ANTIQUITY has had in this epoch-making transition for archaeology in general. From the peculiar point of view of the Classicists, this appeared to be the end of the world. Classical archaeology went, almost overnight, from the status of founding member and elder statesman of the discipline to that of a small contingent struggling to bring up the rear, bogged down with culture-historical norms and obsessed with irrelevant detail. It is as if Classicists had woken up one day to find that everybody else had upped and gone during the night, down a path that they were neither planning nor prepared to follow. To this day, they are still reeling from the shock.

This is probably the key event in the intellectual history of Classical archaeology in the 20th century and ANTIQUITY again bears illuminating witness of the phenomenon. The subfield all but disappeared from the journal. This was a sudden development whose beginning can be dated with some precision to the late 1960s: only six of the papers published between
1966 and 1982 dealt with Greek or Roman subjects. Aegean archaeology fared a bit better, which is not surprising in light of the important part that the journal had played in this field in the previous 15 years, but there too a considerable decline was perceptible. The range of authors in this period was mostly limited to veterans who had published in the journal before, such as David Whitehouse (1983), Barry Cunliffe (1984) and Tim Potter (Potter \& Jackson 1982 ). In the 15 years since the mid 1980s, things improved only marginally: the Aegean contributions continued to trickle in, with remarkable papers by excellent scholars such as Anthony Snodgrass, John Bintliff (Bintliff \& Snodgrass 1988; Bintliff 1984), Tjerd van Andel and Curtis Runnels (Van Andel \& Runnels 1988). But the rest of the discipline was no longer represented. The little that remained came either from people who simply refused to take notice of what happened (such as the author of the only epigraphic paper in the history of the journal) or from researchers pursuing specific interdisciplinary avenues of research. Such is the work of David Peacock $(1989 ; 1994)$ or the reports on trireme reenactments (Tilley 1992; Morrison 1991) or Etruscan archaeoastronomy (Aveni \& Romano 1994).

Thus, aside from what mainstream Classical archaeology would consider fringe researchers and lost jungle patrols, the rest of the discipline has simply ceased to consider ANTIQUITY as a viable outlet for its research, and entrenches itself instead in a handful of specialist journals. This is bluntly put, but it describes a phenomenon that we have to analyse and understand better. I did not collect the data about submissions and acceptances (it would be a very interesting exercise) but a simple count of the number of papers published reveals the sheer magnitude of the process. Classical archaeology had accounted for roughly one in six for the first 50 years of the journal. After that, the rate drops to about one in twenty (FIGURE 2). It is a more than threefold sudden drop, and it would be worse, as we shall see, if one considered Aegean archaeology separately. I am not sure whether there are fewer good submissions or a higher rejection rate. For sure, an explicit editorial countermeasure is detectable in 1986, when a special section is dedicated to Classical archaeology. It is a gallant effort, spearheaded by a strenuous defender of a wider dia- 


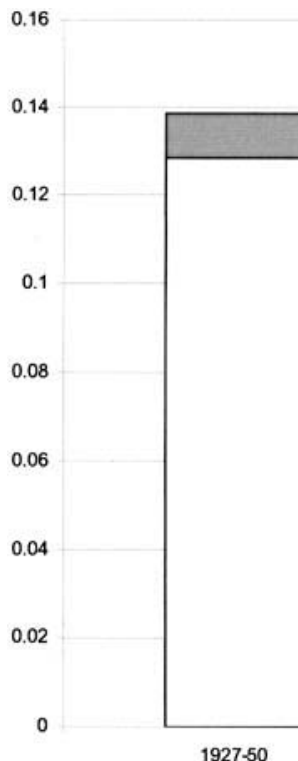

$1927-50$

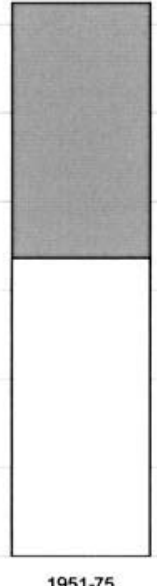

$1951-75$

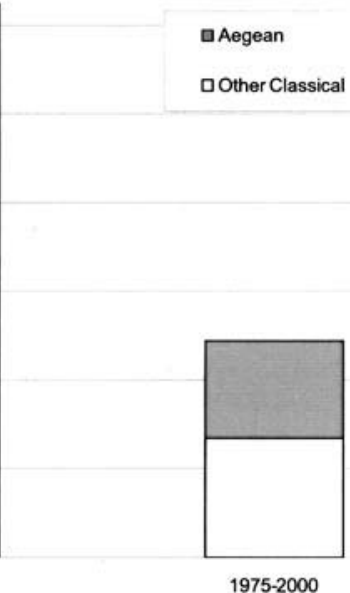

FiguRE 3. Percentage of Aegean and other Classical archaeology articles published. logue among different specialists, such as Anthony Snodgrass, but, as always, the token inclusion only calls more attention to the fact that an entire group is being left out. There is clearly a much stronger underlying intellectual process, which must be fully deconstructed before things can change.

We clearly need to go deeper, even if we do not believe that things need to be patched up between the two sides of the divide. As I said, this is absolutely not a desperate appeal for the return of a Golden Age when the Classical lamb dwelt with the archaeological lion. I am the first to be glad of the departure of a certain runof-the-mill Classical archaeology for greener pastures, but the question is whether we are happy with a situation of almost complete mutual exclusiveness; and this can only be decided on the strength of a better understanding of what actually happened on the intellectual level. And leafing through the old issues again reveals important clues.

While the crisis of Greek and Roman contributions manifests itself blatantly from the 1970 s, its origins can be traced to the previous two decades. If Aegean archaeology is considered separately, it becomes apparent that the decline is already under way in the 1950s, when the frequency of papers dealing with Greece and Rome is less than halved (FIGURE 3). The boom of Minoan and Mycenaean studies and the quality of most of the other Classical con- tributions masks the phenomenon to an extent, but the underlying trend is very striking and significant. The 1970s simply witness the completion of the process, with the Aegeanists largely following their colleagues in their retreat to the ivory towers. So it is really a gradual movement that prevents Classical archaeologists from going in the same direction as that of everybody else in the discipline; and what is remarkable is that this happens in parallel with the development of evolutionary and comparative approaches in archaeology. Such slow tectonic movements were probably barely detectable for those involved, but ANTIQUITY's run not only charts them precisely, but even anticipates them in some respects. We see a journal not happy with simply being up to date like few others, but one that is often way ahead of its time. As comparativists such as Leslie White (1957) and Gordon Willey (1973) become authoritative contributors, the Ward-Perkinses and the Freres begin feeling a bit out of place in what used to be their own home. The more everybody starts thinking in cross-cultural terms (developing in the process a body of theoretical and methodological thought), the further Classicists slide unnoticed towards the stage exit. When David Clarke eventually announces that the emperor has no clothes, those who would rather avoid such unpleasant revelations have been getting ready to leave the party for a generation or so. 
The question then becomes: what is the strong force that keeps processualism and Classical archaeology always at a safe distance from each other? Why can't Classicists join in in the exciting wholesale redefinition of the discipline? Why do they stay out of the passionate debate (to use a euphemism) to sit on a pile of CIL volumes and wonder what all the noise is all about (as in the famous cartoon)? A full answer to these questions would need volumes (which, incidentally, are long overdue), but some general thoughts might lead us in the right direction.

For a start, there are some basic observations, such as the fact that Classical archaeology relies on a vast body of notions and skills that are perceived as absolutely vital to every practitioner. These include time-consuming lores such as a mastery of the ancient languages, an extensive knowledge of Greek and Roman art, architecture, literature and history, at least a smattering of philology, epigraphy and numismatics. It is still widely believed (especially more traditional contexts, such as those in Germany, Italy or the United States) that only once students have acquired a background of this kind can they effectively approach original research questions. This baggage inevitably weighs down curricula and makes it very difficult to introduce courses dealing with all the innovative methodological and theoretical tools that characterize the new approaches.

Another factor is undoubtedly represented by the inherent historicist stance that has been the default theoretical framework for Classical archaeology. Because of that, comparative and evolutionary approaches have always had problems in being adopted for Mediterranean complex cultures in general. The survival of large quantities of written ethnohistory, or 'sources' as they are idiosyncratically called, inevitably shifts the emphasis from big picture reconstructions to the collation of detailed and often eventbased narratives. Significantly, reductionism and oversimplification still rank very high among the mortal sins that a Classicist can commit, while boring the living daylights out of the reader is still absolutely all right.

But deeper than any attachment to a traditional genre of discourse lies a much bigger obstacle to any comparative development in Classical studies. Ever since the Renaissance, this particular segment of the human past has played a unique ideological role in western culture. It is perceived as responsible for key modern acquisitions such as scientific thought, democracy or self-consciousness. It is the golden heritage that makes civilization stand out from savagery. It is the birthright that makes colonialism ethically acceptable (Hingley 2001; Marchand 1996). Classicity must be reverently explored and dusted, but it cannot be compared with, or measured on the same scale as, the rest of the human past. To see it as just another instance of a complex society would completely undermine the cultural edifice of the western world, and radically challenge its claim to dominance. Thus, scholars who deal with Classicity find an interpretative framework that is factorybuilt into the discipline and locked in place by a secular accretion of literature. Tellingly, Classical culture is the only one whose very name is a value judgement.

Because of all this top-heavy ideological baggage, Greek and Roman archaeologists simply could not have lost their innocence even if they had been eager to. They had to remain the Vestals that kept the alive the sacred flame, i.e. an extremely idiosyncratic form of scholarly discourse tailored to fit only that unique and unmistakable cultural context that for the last half-millennium has served as a role model for western society. So, when the rest of the discipline goes down a completely new road, they cannot but stay on the old one. They could share meeting places such as ANTIQUITY with the other archaeologists as long as no cross-cultural claims were made, and the exceptional nature of their subject matter was implicitly recognized by all. When boundaries started to blur, and demeaning comparisons became a possibility, their prejudices (but also those of all the other humanists, of the scholarly institutions and of the public) left them with no option but to hide behind high disciplinary barriers. Only a crack team of Aegeanists is still on the loose, a sort of scouting party, mostly because Minoans and Mycenaeans are too far removed and have been discovered too recently to be heavily encrusted with ideological overtones.

So far, the meek retreat of the innocents. But the bold sceptics aren't entirely blameless either. Having the cultural tools to know better, they tolerated the perpetuation, and even the deepening, of a rift that scars the discipline. No sustained attempt was made at maintain- 
ing contact with the self-exiled. What is much worse, no attempt is still being made at reclaiming that specific and very conspicuous segment of the past to the recent approaches. Pains are taken to try out new models far and wide, including deserts and sub-arctic regions, to open up new dialogues with social scientists and specialists of all kinds, yet Classicists are allowed to sit out this entire cultural phase with barely a shrug (Lees 2002). It is the flip side of the very same ideological bias at work. The new theory of cultural evolution can explain everything except the past of the theorists themselves. Autoreferentiality has always been a tricky game.

This is nowhere as clear as in American universities. Perhaps because this is geographically the area where western culture comes in closer contact with The Other, no confusion of the Classical and the anthropological past can be accepted. The two traditions have been separated from the very beginning and this mutual segregation still goes largely unchallenged (but see now Wiseman 2002). This is particularly remarkable if one considers the dominant role that comparative approaches still have here. American anthropology feeds on just about anything except Greece and Rome. They are like spiky leaves that only a symbiotic species of bookworms can thrive on. And yet the thorns that turn away the strong processual mouths are not real, but only an illusion created by prejudice. It is a piece of the past like any other; it is only its modern use that has been different.

In Europe, as the early years of ANTIQUTTY show us, there has been a bit more dialogue. British county archaeology, for example, appears to have been a safe haven where the Roman period could be considered as just another phase in the national heritage. Crawford himself, in the second year of the journal, challenged the nationalist glorification of the Classical and Christian heritage of western Europe expounded by scholars and publicists like Hilaire Belloc (1924). His argument was a purely archaeological one, focusing upon the transformations taking place at the local level in the long run. This level-headed, down-toearth approach was the only possible critique, at the time, of the dominant ideology for which Roman-ness is what sets Westerners apart from the barbarians inhabiting the rest of the world.
It is clear to Crawford that the myth of the 'debt to Rome', which he questions from the title onwards, is nothing but an obstacle to the reconstruction of integrated narratives. Notwithstanding his action, the colonialist bias is still with us and in the journal. So when we try to treat Greece and Rome like any other cultural context we hit an invisible intellectual barrier that prevents any contamination.

Paradoxically, precisely because of its peculiar status, the relevance of Classics has been steadily declining everywhere, not just in the pages of the journal. After all, why should a paltry millennium and a half in a couple of Mediterranean peninsulas account for a third of the faculty in a department of archaeology, or a sixth of the papers published in ANTIQUITY? What is regretted here is not that Classical archaeology was down-sized, but that it was not assimilated, incorporated or even simply interacted with.

So where do we go from here? How should a journal such as ANTIQUITY deal with Classical archaeology? In other words, how should archaeology as a whole consider the anomaly presented by Greece and Rome? As I hope is clear by now, the point of all this is not to bring back a quota for Classical archaeology, be it onesixth or any other. The question is, rather, whether there is any reason still to be troubled if we approach these contexts with the tools that everybody else uses. Do we still really need to uphold the uniqueness of that part of our heritage, to have Greeks and Romans as role models? This seems hardly to be the case. The nature of western culture has changed. Among its many boons, decolonization has given us world archaeology. But until we dare to let those ancestors down from the pedestals we erected for them, to let the Classics become ordinary, the last fumes of the colonial hangover will remain undispelled.

Good journals reflect the current discourse, excellent ones anticipate it. ANTIQUITY has often been ahead of its times and can be so again. It might be the ideal venue to begin patching up a split that has little reason to exist any longer in archaeology. It goes without saying that Classicists have more ground to cover, but they may also have amazing discoveries to make, once their subject matter is reconsidered with fresh eyes. All the other archaeologists only stand to gain from the integration within their broad 
reconstructions of the one bit of the human past that has so far been left out. More importantly, deconstructing the traditional views of Greeks and Romans may reveal crucial aspects of the political use of history and archaeology. By removing the last colonialist underpinning of

\section{References}

ASHBY, T. 1928. Three Italian archaeological congresses, Antiquity $2: 337$.

AvENI, A.F. \& G. ROMANO. 1994. Orientation and Etruscan ritual, Antiquity 68: 545-63.

BeLloc, H. 1924. Europe and the Faith. London: Constable.

BinTLIFF, J. \& A. SNODGRASS. 1988. Mediterranean survey and the city, Antiquity 62:57-71.

BINTLIFF, J. 1984. Structuralism and myth in Minoan studies, Antiquity 58: 33-38.

BoARDMAn, J. 1960. The multiple brush, Antiquity 34: 85-9.

BRADFORD, J. 1947. Etruria from the air, Antiquity 21: 74.

1949. 'Buried landscapes' in Southern Italy, Antiquity 23: 58.

CALZA, G. 1933. Ostia in the light of recent discoveries, Antiquity 7: 405-9.

CHADwick, J. 1953. Greek records in the Minoan script, Antiquity 27: 196-200.

1959. Minoan Linear A: a provisional balance sheet, Antigvity 33: 269-78.

Collingwood, R.G. 1927. Roman frontier in Britain, Antiquity 1: $15-30$.

1930. A newly-discovered Roman site in Cumberland, aix photograph, Antiquity 4: 472-7.

1932. Two Greek fortresses in Sicily, Antiquity 6: 261-75.

CRAWFORD, O.G.S. 1928. Our debt to Rome? Antiquity 2: 17388.

1934. Sidonius and his times, Antiquity 8: 81-84.

CUNLIFFE, B. 1965. Fishbourne (1961-4), Antiquity 39: 177-83.

1966. The temple of Sulis-Minerva at Bath, Antiquity 40: 199-204.

1984. Images of Britannia, Antiquity 58: 175-8.

FRERE, S.S. 1964. Verulamium, three Roman cities, Antiquity 38: 103-12.

GjerstaD, E. 1928. The Swedish excavations in Cyprus, Antiquity 2: 189-91.

1952. Stratigraphic excavations in the Forum Romanum, Antiquity 26: 60-64.

HiNGLEY, R. (ed.) 2001. Images of Rome. Portsmouth: JRA.

HOOD, M.S.F. 1962. The Knossos tablets: a complete view, Antiquity 38-40.

KENYON, K. 1952. Early Jericho, Antiquity 26: 116-22.

Krautheimer, R. \& S. CorbetT. 1960. The Constantinian basilica of the Lateran, Antiquity 34: 201-6.

LEES, S. 2002. Separation versus a Larger Vision, The Archaeological Record 2: 11-13.

MARCHAND, S.L. 1996. Down from Olympus: archaeology and philhellenism in Germany, 1750-1970. Princeton (N)): Princeton University Press.

MARINATOS, S. 1939. The volcanic destruction of Minoan Grete, Antiquity 13: 425-39. the discipline, we may be able to move in unexpected directions and perhaps even change our understanding of how and why we need to explore our past.

And, in doing all this, we would follow another of Crawford's visionary leads.

MatTingley, H. 1934. Britannia, Antiquity 8: 381-94.

MORRISON, J.S. 1991. Ancient Greek measures of length in nautical contexts, Antiquity 65: 298-305.

NYLANDER, C. 1963. The fall of Troy, Antiquity 37: 6-11.

Pallottino, M. 1962. The Etruscan Lion, Antiquity 36: 201-5.

PEACOCK, D.P.S. 1989. The mills of Pompeii, Antiquity 63: 20514.

PEACOCK, D.P.S., O. WILLIAMS-THORPE, R.S. THORPE \& A.G. TINDLE. 1994. Mons Claudianus and the problem of the 'granito del foro': a geological and geochemical approach, Antiquity 68: 209-30.

POTTER, T.W. \& R.P.G. JACKSON. 1982. The Roman site of Stonea, Cambs, Antiquity 56: 111-20.

RANDALL-MAClver, D. 1927. The Etruscans, Antiquity 1: 159-71. 1928a. Forerunners of the Romans, Antiquity 2: 26-36.

1928b. Forerunners of the Romans II, Antiquity 2: 133-46.

SchNapP, A. 1993. La conquête du passé: aux origines de l'archéologie. Paris: Carré.

SHEAR, T.L. 1933. Remarkable discoveries in the Athenian Agora, Antiquity 7: 261-267.

THLey, A. 1992. Three men to a room - a completely different trireme, Antiquity 66: 599-611.

TRIGGER, B. 1989. A history of archaeological thought. Cambridge: Cambridge University Press.

VAN ANDEL, T.H. \& C. RUNNELS. 1988. An essay on the 'emergence of civilization' in the Aegean world, Antiquity 62: $234-47$.

VENTRIS, M. 1953. A note on decipherment methods, Antiquity 27: 200-206.

VITA-FInZI, C. 1961. Roman dams in Tripolitania, Antiquity 35: $14-20$.

WACE, A.J.B. 1936. Mycenae, Antiquity 10: 405-16.

1940. The Treasury of Atreus, Antiquity 14: 233.

WARD-PERKINS, J.B. 1942. Problems of Maltese prehistory, Antiquity 19: 19-35.

Webster, T.B.L. 1957. Mycenaean records: a review, Antiq uity $31: 4-8$.

WHITE, K.D. 1963. Wheat-farming in Roman times, Antiquity $202-12$.

1965. The productivity of labour in Roman agriculture, Antiquity 102-7.

WHITE, L.A. 1957. Evolution and diffusion, Antiquity 31: 21418.

WhITEHOUSE, D. 1983. The future of ancient Rome, Antiquity 57: $38-44$

WiLlEY, G.R. 1973. Man, settlement, and urbanism, Antiquity 47: 269-279.

Wiseman, J. 2002. Archaeology as an academic discipline, The Archaeological Record 2: 8-11. 